\title{
REE, Nd, Sr and Eu isotope geochemistry of anorthosite at Sancheong area, Korea
}

\author{
SEUNG-Gu LEE ${ }^{1}$, YOUNG-ROK PARK ${ }^{2}$
}

${ }^{1}$ KIGAM, Daejeon 34132, Korea, sgl@kigam.re.kr ${ }^{2}$ Kangwon National University, Chuncheon24341, yrpark@kangwon.ac.kr

Anorthosite is a gabboric igneous rock containing plagioclase as the main constituent mineral and less than $10 \%$ of colored minerals such as pyroxene, olivine or amphible. Most of the anorthosite on the earth is distributed in the Archean formation. The terrestrial anorthosite is compared to lunar anorthosite which is one of the lunar constitutent rocks. One of the most striking geochemical properties of the anorthosite is that rge Eu positive anomaly associated with plagioclase is significantly developed. Currently, most of the anorthosite that is widely distributed in the world are not single intrusive rock but rather a complex composed of several types of intrusive rocks.

Anorthosite in Hadong-Sancheong area in the Korean Peninsula also is a complex of massif-type. Its formation is age is $1.7 \sim 1.86 \mathrm{Ga}[1,2]$. However, there are few of the data related trace and rare earth elements from the HadongSancheong anorthosite in the Korean Peninsula. Recenlty, Lee \& Tanaka[3] developed a new method for determining $\mathrm{Eu}$ isotopic ratio using MC-ICP-MS. In this paper, we report a geochemical characteristic of rare earth element distribution pattern and $\mathrm{Sr}-\mathrm{Nd}-\mathrm{Eu}$ isotope system. In particular, we discuss an geochemical implication of $\mathrm{Eu}$ stable isotope fractionation and $\mathrm{Eu}$ anomaly in the chondrite-normalized REE pattern.

[1] Kwon S-T. \& Jeong J-G. (1990) Jour. Geol. Soc. Korea, v. 26, 341-349. [2] Lee et al. (2014) Terra Nova, v. 26, 408-416. [3] Lee S-G. (2019) Spectrochim. Acta Part B, 156, $42-50$ 